\section{ARE YOUR SENSITIVITY PATIENTS MAKING THE RIGHT CHOICES?}

Sensodyne True White, a new ultra-low abrasion fluoride toothpaste specifically developed to be suitable for dentine hypersensitivity sufferers and to gently lift and prevent tooth stain with twice-daily brushing, is poised to help address this. ${ }^{1-3}$

The Sensodyne True White formulation actively lifts and prevents extrinsic dental
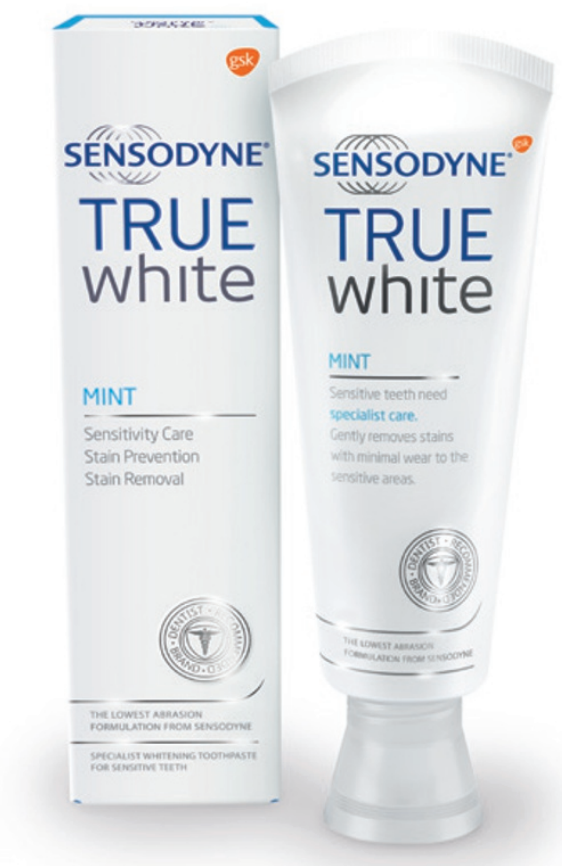

stains and a study has shown it is as gentle on exposed dentine as brushing with water after 10 days of brushing ( $>00.05) .{ }^{4}$ It contains $5 \%$ sodium tripolyphosphate to gently remove and prevent extrinsic tooth stains with twice daily brushing, ${ }^{1-3}$ with minimal wear to sensitive areas of the teeth. ${ }^{4}$

An Ultra-low Abrasion Formula

Sensodyne True White is different to many other daily use whitening toothpastes currently available as it does not contain dental abrasives and has an ultra-low RDA of just 13, and is more than 10 times less abrasive than many everyday whitening toothpastes. ${ }^{9}$ Dentine can be up to 10 times softer than enamel, and is more susceptible to abrasive wear. ${ }^{10}$ Tooth brushing with higher abrasivity toothpastes, such as many daily-use whitening toothpastes, may result in further wear of the exposed dentine.

Find out more about Sensodyne True White by visiting www. gskdentalprofessionals.co.uk/TrueWhite. ${ }^{1}$

Shellis RP et al. J Dent 2005; 33: 373-324

GSK data on file, DOF: Z2860416

GSK data on file DOF: 72860435

Addy M Int Dent J 2002 52: 367-375

Vallittu PK, J Dent 1996; 24: 335-338

GSK data on file

. Pickles M J. Toothwear. In: Duckworth 2006; 19: $86-104$
GSK data on file, DOF: 22860415

West NX et al. J Dent 2013: 41: 847-851
Joiner J. Dentistry 2010; $\mathbf{3 8}: 17-e 24$

\title{
YOUR PARTNER IN ORAL HEALTH
}

Visit Colgate at this year's BDIA Dental Showcase on stand G95. Discover the latest in whole-mouth protection against dental plaque with Colgate Total toothpaste and its sustained release technology, helping to control plaque regrowth for 12 hours.' View the Colgate ProClinical electric toothbrush range to see how they can achieve superior ${ }^{2}$ plaque removal and healthier teeth and gums for all your patients, and hear about the exclusive dental discounts you and your practice can enjoy across the Colgate ProClinical electric toothbrush range. The professional team will also be on hand to demonstrate how you and your team can tap into a world of expertise by visiting the Colgate Professional website www.colgateprofessional.co.uk. Find out about the latest features and what's on offer to support your patients and professional practice, including requesting patient toothpaste samples. Put your plaque fighting skills to the test with the Colgate Total game and collect your complimentary personalised poster. *

\section{References:}

Fine DH, Sreenivasan PK, McKiernan M, et al. J Clin Periodontol. 2012; 39: 1056-1064

2. Vs a manual, flat-trimmed toothbrush * One poster per

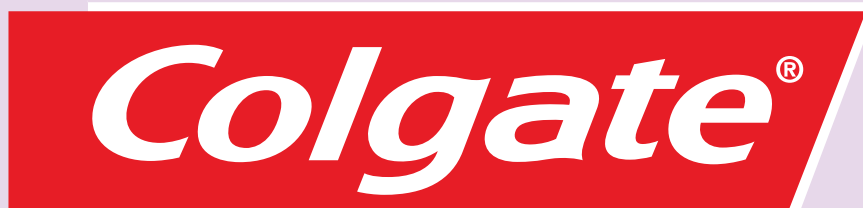

\section{REDUCING THE RISK OF MISALIGNED TEETH}
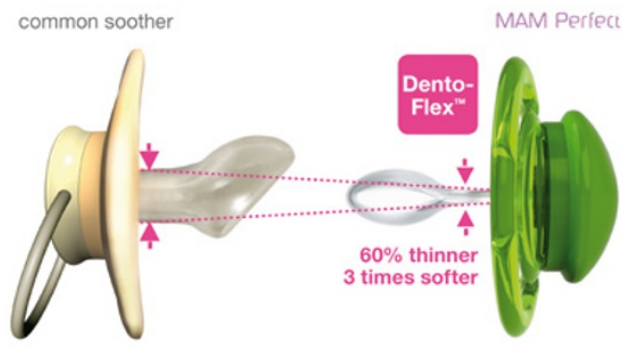

Healthcare professionals working with parents of babies and toddlers who are using a soother can now introduce them to the MAM Perfect soother that supports healthy teeth and jaw development.

Those in the dental team know that many regular soothers can exert too

much pressure on the teeth and jaws because of material drawbacks and sub-optimal shapes. Through intensive co-operation with medical experts and the latest findings from a longitudinal scientific study, it has been confirmed that the MAM Perfect pacifier positively supports healthy tooth and jaw development.

In the longitudinal study 86 children. ranging from 16 to 24 months of age, were randomly assigned into three groups. At the beginning of the test phase, group one switched from their previously used soothers to the MAM Perfect, which has a teat neck crosssection of approximately 2.78 millimetres and is considered the thinnest and most adaptable on the market.? The study concluded that, whilst weaning from a soother completely was best, switching to the MAM Perfect had less impact than continuing to use a conventional soother.

Healthcare professionals must consider that weaning off a soother is often difficult. Many children use their thumb in place of a soother, and the resulting negative effects on the teeth and jaw have been clearly shown in numerous studies.

The Austrian Research Institute (OFI) and the Vienna Dental University Clinic. 37 models in three testing groups in comparison. 